\title{
STUDY OF POST-CRACKING TORSIONAL BEHAVIOUR OF HIGH-STRENGTH REINFORCED CONCRETE BEAMS WITH A FERROCEMENT WRAP
}

\author{
Gopal Charan BEHERA ${ }^{*}$, Tippabhotla Durga Gunneswara RAO², Chittem Butchi Kameswara RAO ${ }^{2}$
}

\section{Abstract}

The post-cracking behaviour of structures subjected to torsion can be well predicted by Hsu's softened truss model. The softened truss model is applicable to structures having symmetry in their material properties on all four sides. Wrapping on three faces is a common phenomenon when the top face is provided with a flange or slab. Such a wrapping on three faces of a beam is referred to as a "U" wrap. "U" wraps are better wrapping strategies for distressed structures, as their top face is not accessible for many structures. The material property of an unwrapped face differs from the rest of wrapped faces. For the effective use of wrapping, the unwrapped face needs to be provided with a material having a higher resistance to tension and shear. For this, high-strength concrete in the core is a better option. Here, an attempt is made to predict the torsional capacity of " $U$ " wrapped high-strength concrete beams having an asymmetry in the material using a softened truss model with suitable modifications of the material properties. Efficient algorithms are proposed for the solution of simultaneous equations. The predictions are found to be in good agreement with the experimental test results.
Address

1 Civil Engineering Department, BIET, Barapada, Bhadrak, Odisha, India-756113

2 Civil Engineering Department, NIT Warangal, A.P., India, Pin506021

* Corresponding author: beheragb@yahoo.co.in

\section{Key words}

- High-strength concrete,

- torsional strength,

- twist,

- toughness,

- stiffness.

\section{INTRODUCTION}

In the recent past, the world has witnessed many natural calamities. Distressed structures need to be retrofitted rather than demolished (Adrian and Riadh, 2007; Ghobarah and Ghorbel, 2002). Wrapping with composites is an effective way of retrofitting to address the torsional deficiency of distressed reinforced concrete (RC) structures and to change the failure mode from brittle to ductile. FRP wrapping is a better solution to protect distressed structures against shear, torsion or bending (Adrian and Riadh, 2006; Mehran and Harid, 2007). It is more costly. Ferrocement, a composite material which possesses a better distribution of strain and crack- arresting characteristics (ACI-549 R, 1997) can strengthen reinforced concrete structures effectively in a similar way to that of FRP. Ferrocement is a relatively cheaper material compared to FRP; therefore, ferrocement "U" wraps can be a substitute for developing countries. Research has attained its pace for the quantification of a ferrocement composite as a wrapping against shear, bending and axial forces (Bansal et al., 2007). No such analytical model is available to quantify the torsional strength of ferrocement as a wrapping material. Again, for the effective use of wraps, the cracking should be initiated from the wrapping face. To avoid the initiation of cracking from an unwrapped face, the concrete must be of a higher strength. High-strength concrete (HSC) possesses some characteristics and properties that may differ from those of normal-strength concrete (Rasmussen, 1995). Distressed beams cannot be wrapped on all four sides, which are required to resist torsion due to the presence of flanges (slabs). "U" wraps are a solution for this problem (Saravanan and Belarbi, 2002). The torsional behaviour of 


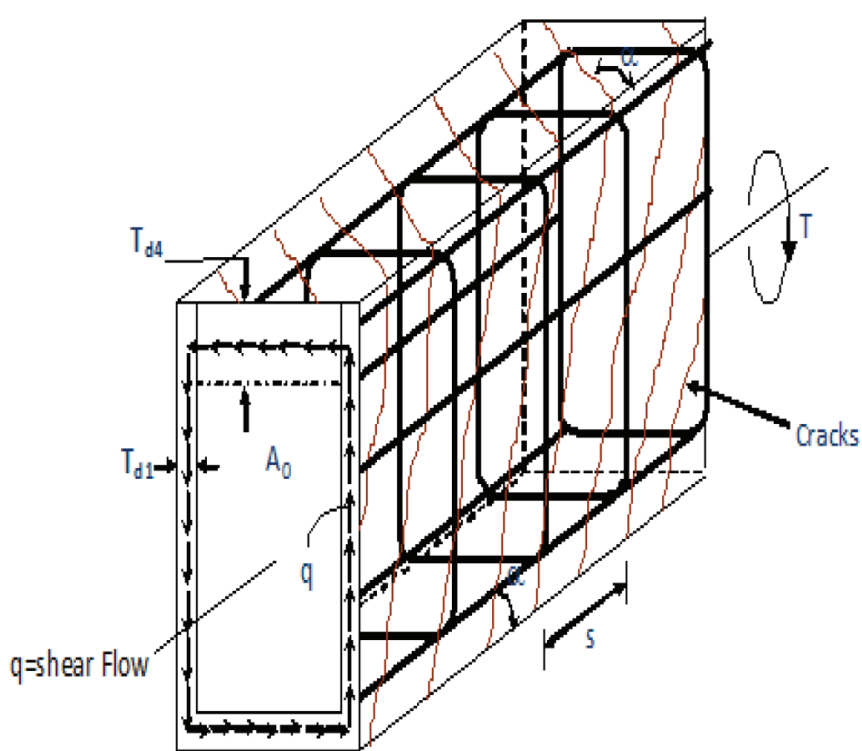

Fig. 1 Cracked beam section due to torsion.

"U" wrapped beams up to cracking is well covered by (Behera et al., 2008). Beyond cracking, the softened truss model by Hsu is a powerful tool for the analysis of the torsional behaviour of beams with symmetry in their material properties. As there is asymmetry in the material properties of ferrocement "U" wrapped HSC reinforced beams, a softened truss model cannot be directly applied for the post-cracking stage. So, here an attempt is made for the prediction of torsional strength in the post-cracking stage by applying Hsu's softened truss model with suitable modifications in the material properties.

\subsection{Post-Cracking Stage of "U" Wrapped RC High- Strength Beams}

The torque-twist response of " $U$ " wrapped reinforced concrete beams up to cracking is well predicted by the equations (Behera et al., 2008). After the cracking, the softened truss model by (Hsu, 1988) is applied for the prediction of torsional strength with suitable modifications in the material properties.

\subsubsection{Formulation of Problem}

After cracking, "U" wrapped beams can be analyzed as a thin tube (Hsu, 1988; Rao and Seshu, 2003; Rao and Seshu, 2005; Rao and Seshu, 2006). Diagonal cracks separate the concrete and ferrocement into a series of diagonal struts. The longitudinal and transverse reinforcements keep the cracked pieces of concrete and ferrocement together in their respective faces (Hsu, 1988; Leu and Lee, 2000). The concrete struts are subjected to compression, and the steel bars act as tension links in the concrete face, thus forming a truss action in the concrete face. The mortar on the other three faces acts as strut and wire meshes, with the steel reinforcement acting as a tension link in the ferrocement faces. The propagation and growth of cracks are diminished in the ferrocement faces in comparison to the unwrapped concrete face due to the presence of the ferrocement, as the ferrocement has a better crack-arresting ability. The beams with ferrocement "U" wraps subjected to torsion after cracking can be analyzed as hollow tubes of variable thicknesses on the periphery with an equal shear flow 'q' as shown in Fig.1 due to the asymmetry in the material. After cracking, the hollow tube thickness can be taken as $\mathrm{T}_{\mathrm{d} 1}$ on the three ferrocement-wrapped faces and $\mathrm{T}_{\mathrm{d} 4}$ on the top concrete face.

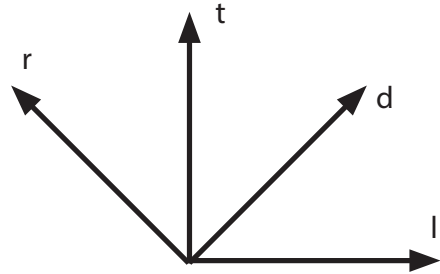

Fig. 2 Co-ordinate system.

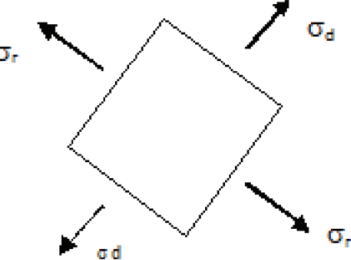

Fig. 3 Applied stresses.
The theories available to date in the literature for the prediction of the torsional strength of beams are based on an equal thickness of a shear flow tube due to the homogeneity in the material. When a "U" wrap is present, the same theories cannot predict the torsional strength due to the asymmetry in the material. The thickness of the shear flow tube will vary according to the shear-resisting capacity of the materials present on the outer periphery of the beam. So, the shear flow thickness of the reinforced concrete portion will be different from that of the ferrocement faces. The shear flow is the same on all the faces, but the shear stress is different for different faces. So, the beam can be idealized as a space truss with co-ordinate systems as shown in (Figs. 2 and 3). The post-cracking behaviour of ferrocement "U" wraps can now be analyzed by the softened truss model with necessary modifications in the equations.

\subsubsection{Assumptions}

i. After cracking, the tensile force in the longitudinal and transverse directions is taken by the steel bars in the concrete core for the unwrapped portion. The same is resisted by the mortar, steel bars and GI wire mesh in the ferrocement shell. The tensile stress of the concrete is ignored, but the tensile strength of the mortar is taken into account.

ii. A perfect bond exists between the concrete and the ferrocement.

iii. The diagonal concrete on the top face and the mortar on the other three sides only take axial compression.

In Fig. 1 the concrete top face is treated as a fourth face and has a different thickness than the other three wrapped faces. The ferrocement-wrapped faces are assumed to have an equal thickness due to the symmetry of the material.

Fig. 2 represents the coordinate system used in the analysis. There are two main coordinate directions: the l-t direction represents the longitudinal and transverse directions; whereas, the d-r direction represents the principal stress directions respectively. A torsional load induces a biaxial tension-compression state along the diagonal directions. It is assumed that the compressive stress $\sigma_{d}$ of the biaxial state acts along direction ' $d$ ', whereas, the tensile stress $\sigma_{\mathrm{r}}$ acts in the ' $r$ ' direction as shown in (Fig. 3). A ferrocement composite is made up of a mortar matrix and mesh reinforcement, which is finely dispersed across the section. Therefore, the resistance provided by the ferrocement section can be idealized as the sum of the resistance provided by the mortar matrix and mesh reinforcement (Fig. 4).

\subsubsection{Equilibrium Equations}

Considering a small element in the concrete and ferrocement faces, the equilibrium condition results in the following equations:

$$
q=\frac{T}{2 A_{\circ}}
$$

where $\mathrm{q}=$ shear flow, $\mathrm{T}=$ Torsional moment, $\mathrm{A}_{0}=$ Area enclosed by the centre line of the cracked tube. 


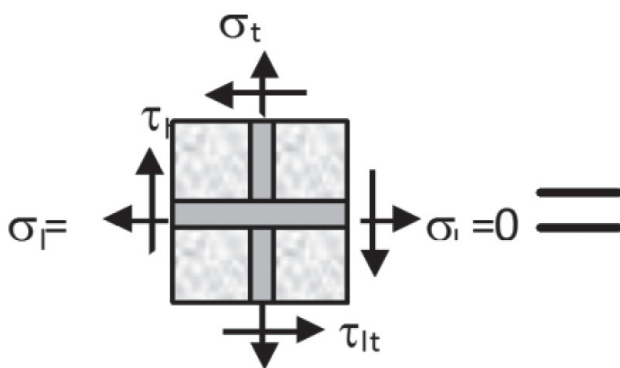

Composite section

Fig. 4 Idealisation of the composite.

a) Longitudinal direction

$$
\sigma_{\mathrm{d} 1} \cos ^{2} \alpha_{1}+\sigma_{\mathrm{r} 1} \sin ^{2} \alpha_{1}+\rho_{11} F_{11}=0
$$

for the ferrocement face

$$
\sigma_{\mathrm{d} 4} \cos ^{2} \alpha_{4}+\rho_{14} F_{14}=0
$$

for the concrete face where $\rho_{11}=\frac{A_{11}}{T_{d 1} d} A_{11}=A_{l w 1}+A_{1 s 1}$

$$
\begin{aligned}
& \rho_{14}=\frac{A_{14}}{T_{d 4} b} \\
& b=B-T_{d 1} \\
& d=H-\frac{T_{d 1}}{2}-\frac{T_{d 4}}{2}
\end{aligned}
$$

\section{b) Transverse direction}

$$
\sigma_{\mathrm{d} 1} \sin ^{2} \alpha_{1}+\sigma_{\mathrm{r} 1} \cos ^{2} \alpha_{1}+\rho_{\mathrm{t} 1} F_{\mathrm{t} 1}=0
$$

for faces1, 2 and 3 (ferrocement faces)

$$
\sigma_{\mathrm{d} 4} \sin ^{2} \alpha_{4}+\rho_{\mathrm{t} 4} F_{\mathrm{t} 4}=0
$$

for $4^{\text {th }}$ face (concrete face)

$$
\begin{gathered}
\rho_{\mathrm{t} 1}=\frac{A_{\mathrm{t} 1}}{T_{\mathrm{d} 1} \mathrm{~s}_{\mathrm{w}}} \\
\rho_{\mathrm{t} 4}=\frac{A_{\mathrm{t} 4}}{T_{\mathrm{d} 4} \mathrm{~s}_{4}}
\end{gathered}
$$

where $\sigma_{\mathrm{d} 1}$ and $\sigma_{\mathrm{d} 4}$ are the principal compressive stresses in faces 1 and 4 respectively.

$\sigma_{\mathrm{r} 1}$ and $\sigma_{\mathrm{r} 4}$ are the principal compressive stresses in faces 1 and 4 respectively.

$\rho_{11}$ and $\rho_{14}$ are the reinforcement ratio in the longitudinal direction in faces 1 and 4 respectively.

$\rho_{\mathrm{t} 1}$ and $\rho_{\mathrm{t} 4}$ are the reinforcement ratio in the transverse direction in faces 1 and 4 respectively.

$\mathrm{A}_{11}=$ Area of steel reinforcement along the longitudinal direction in the ferrocement face taking the steel bars and wire mesh.

$\mathrm{A}_{14}=$ Area of steel reinforcement along the longitudinal direction in the concrete face.

$F_{11}$ and $F_{14}$ are the stresses in the longitudinal reinforcement in faces 1 and 4 respectively.

$\mathrm{F}_{\mathrm{t} 1}$ and $\mathrm{F}_{\mathrm{t} 4}$ are the stresses in the transverse reinforcement in faces 1 and 4 respectively.

$a_{1}, \alpha_{4}$ crack angle along the ferrocement face and concrete face respectively.

$\mathrm{A}_{\mathrm{t} 1}=\mathrm{A}_{\mathrm{twl}}+\mathrm{A}_{\mathrm{ts}}$

$\mathrm{A}_{\mathrm{t} 1}=$ Area of steel reinforcement along the transverse direction in the ferrocement face taking the steel bars and wire mesh.

$\mathrm{A}_{\mathrm{t} 4}=$ Area of steel reinforcement along the transverse direction in the concrete face.

$\mathrm{A}_{\mathrm{tw1}}=$ Area of one wire in the mesh

$\mathrm{A}_{\mathrm{ts} 1}=$ Equivalent Area of steel bar in the transverse direction of the ferrocement face calculated for a spacing of $\mathrm{s}_{\mathrm{w}}$ ( ing of the wire in the wire mesh)

c) Shear direction

$$
q=\left(\sigma_{\mathrm{d} 1}-\sigma_{\mathrm{r} 1}\right) \sin \alpha_{1} \cos \alpha_{1}
$$

for $1^{\text {st }}, 2^{\text {nd }}$ and $3^{\text {rd }}$ faces (Ferrocement)

$$
\mathrm{q}=\left(\sigma_{\mathrm{d} 4}-\sigma_{\mathrm{r} 4}\right) \sin \alpha_{4} \cos \alpha_{4}
$$

for $4^{\text {th }}$ face (Concrete face)

Generally $\sigma_{\mathrm{r} 1}$ and $\sigma_{\mathrm{r} 4}$ can be taken as zero, where $\sigma_{\mathrm{r} 1}$ is the tensile stress along the ' $r$ ' direction for the ferrocement face, and $\sigma_{\mathrm{r} 4}$ is the tensile stress of the concrete along the ' $r$ ' direction under the bi-axial compression-tension state. The actual calculation of $\sigma_{\mathrm{r} 1}$ is given in Equation 32. Combining Equations 6 and 7 gives

$$
\left(\sigma_{\mathrm{d} 1}-\sigma_{\mathrm{r} 1}\right) \mathrm{T}_{\mathrm{d} 1} \sin 2 \alpha_{1}=\sigma_{\mathrm{d} 4} \mathrm{~T}_{\mathrm{d} 4} \sin 2 \alpha_{4}
$$

\subsubsection{Compatibility equations}

In the softened truss model it is assumed that the section under consideration is completely cracked. Therefore, the Mohr's circle of strains cannot be applied due to its basic requirement of continuity of the material. However, it is assumed here that the Mohr circle of strains is also applicable in the cracked stage. These strains also include the crack width in the strain measurement. These strains are known as smeared strains.

For the ferrocement face

$$
\begin{aligned}
& \varepsilon_{\mid 1}=\varepsilon_{\mathrm{d} 1} \cos ^{2} \alpha_{1}+\varepsilon_{\mathrm{r} 1} \sin ^{2} \alpha_{1} \\
& \varepsilon_{\mathrm{t} 1}=\varepsilon_{\mathrm{d} 1} \sin ^{2} \alpha_{1}+\varepsilon_{\mathrm{r} 1} \cos ^{2} \alpha_{1} \\
& \gamma_{\mathrm{lt} 1}=\left(\varepsilon_{\mathrm{d} 1}-\varepsilon_{\mathrm{r} 1}\right) \sin 2 \alpha_{1}
\end{aligned}
$$


For the concrete face

$$
\begin{aligned}
& \varepsilon_{14}=\varepsilon_{\mathrm{d} 4} \cos ^{2} \alpha_{4}+\varepsilon_{\mathrm{r} 4} \sin ^{2} \alpha_{4} \\
& \varepsilon_{\mathrm{t} 4}=\varepsilon_{\mathrm{d} 4} \sin ^{2} \alpha_{4}+\varepsilon_{\mathrm{r} 4} \cos ^{2} \alpha_{4} \\
& \gamma_{\mathrm{It} 4}=\left(\varepsilon_{\mathrm{d} 4}-\varepsilon_{\mathrm{r} 4}\right) \sin 2 \alpha_{4}
\end{aligned}
$$

$\varepsilon_{11}, \varepsilon_{14}=$ average strain in the "l" direction in faces 1 and 4 respectively

$\varepsilon_{\mathrm{t} 1}, \varepsilon_{\mathrm{t} 4}=$ average strain in the " $\mathrm{t}$ " direction in faces 1 and 4 respectively

$\varepsilon_{\mathrm{d} 1}, \varepsilon_{\mathrm{d} 4}=$ average principal strain in the "d" direction in faces 1 and 4 respectively.

$\varepsilon_{\mathrm{r} 1}, \varepsilon_{\mathrm{r} 4}=$ average principal strain in the "r" direction in faces 1 and 4 respectively.

$\gamma_{1+1}, \gamma_{1+4}=$ average shear strain in the "l-t" direction in faces 1 and 4 respectively.

From Hsu's softened truss model, the curvature $Y_{1}$ of the diagonal ferrocement strut can be related to the twist angle $\theta$ as per the following equations.

$$
\psi_{1}=\theta \sin 2 \alpha_{1}
$$

In the same way as for the concrete face, the curvature $\Psi_{4}$ can be written as

$$
\psi_{4}=\theta \sin 2 \alpha_{4}
$$

From the bending of the concrete strut the curvature can be related to the maximum strain by

$$
\begin{aligned}
& \psi_{1}=\frac{\varepsilon_{\mathrm{ds} 1}}{T_{\mathrm{d} 1}} \\
& \psi_{4}=\frac{\varepsilon_{\mathrm{ds} 4}}{T_{\mathrm{d} 4}}
\end{aligned}
$$

$\varepsilon_{\mathrm{ds} 1}, \varepsilon_{\mathrm{d} 4}=$ maximum principal strain in the "d" direction in faces 1 and 4 respectively.

Because of the linear strain distribution, the maximum strains $\varepsilon_{\mathrm{ds} 1}$, $\varepsilon_{\mathrm{ds} 4}$ can be related to the average strains $\varepsilon_{\mathrm{d} 1}$ and $\varepsilon_{\mathrm{d} 4}$ by the following equations;

$$
\begin{aligned}
& \varepsilon_{\mathrm{ds} 1}=2 \varepsilon_{\mathrm{d} 1} \\
& \varepsilon_{\mathrm{ds} 4}=2 \varepsilon_{\mathrm{d} 4}
\end{aligned}
$$

combining the equations from (15) to (20),

$$
\theta=\frac{2 \varepsilon_{\mathrm{d} 1}}{T_{\mathrm{d} 1} \sin 2 \alpha_{1}}=\frac{2 \varepsilon_{\mathrm{d} 4}}{T_{d 4} \sin 2 \alpha_{4}}
$$

The twist can be related to the shear strain using Bredt's equation as presented by (Hsu, 1984):

$$
\theta=\frac{2 d+b}{2 A_{0}} \gamma_{\mid t 1}+\frac{b}{2 A_{0}} \gamma_{l t 4}=\frac{\varepsilon_{d s 4}}{T_{d 4} \sin 2 \alpha_{4}}
$$

\subsubsection{Constitutive laws for the materials}

The equilibrium and compatibility conditions of the softened truss model remain the same for all kinds of materials. However, the material law changes with the change in the constitutive material.
This is due to the variation in the stress-strain response of the materials under tension and compression.

\section{a.) Longitudinal reinforcement}

The stress in the longitudinal reinforcement can be related to their strains. The longitudinal strain or transverse strain in the reinforcement is the same as the strain of the ferrocement mortar or concrete surrounding the reinforcement in that direction.

$$
\begin{aligned}
& F_{I 1}= \begin{cases}E_{s} \varepsilon_{11} & \text { if } \varepsilon_{11} \leq \varepsilon_{\mid \mathrm{y} 1} \\
F_{\mathrm{ly} 1} & \text { if } \varepsilon_{11}>\varepsilon_{\mathrm{ly} 1}\end{cases} \\
& F_{\mid 4}= \begin{cases}E_{\mathrm{s}} \varepsilon_{14} & \text { if } \varepsilon_{14} \leq \varepsilon_{\mid \mathrm{y} 4} \\
F_{\mathrm{ly} 4} & \text { if } \varepsilon_{14}>\varepsilon_{\mathrm{ly} 4}\end{cases}
\end{aligned}
$$

\section{b.) Transverse reinforcement}

The strain in the transverse reinforcement is the same as the surface strain in the transverse direction on that face on the concrete or mortar, assuming a perfect bond between them.

$$
\begin{aligned}
& F_{t 1}= \begin{cases}E_{s} \varepsilon_{t 1} & \text { if } \varepsilon_{t 1} \leq \varepsilon_{t y 1} \\
F_{t y 1} & \text { if } \varepsilon_{t 1}>\varepsilon_{t y 1}\end{cases} \\
& F_{t 4}= \begin{cases}E_{s} \varepsilon_{t 4} & \text { if } \varepsilon_{t 4} \leq \varepsilon_{t y} 4 \\
F_{t y 4} & \text { if } \varepsilon_{t 4}>\varepsilon_{t y 4}\end{cases}
\end{aligned}
$$

\section{c.) Compression of the ferrocement struts}

For the ferrocement faces, the compressive stress-strain diagram for the bi-axial state of tension and compression is taken into account. The softening coefficient for the stress and strain of the ferrocement by (Mansur and Abdullah, 1998) is included for an evaluation of the same.

$$
\sigma_{\mathrm{d} 1}=\frac{1}{\varepsilon_{\mathrm{ds} 1}} \int_{0}^{\varepsilon_{\mathrm{ds} 1}} F_{\mathrm{c} 1} \xi_{\sigma}\left[\frac{1.77 \frac{\varepsilon_{\mathrm{ds} 1}}{\varepsilon_{\mathrm{f}} \xi_{\varepsilon}}}{1-0.23 \frac{\varepsilon_{\mathrm{ds} 1}}{\varepsilon_{\mathrm{f}} \xi_{\varepsilon}}+\left(\frac{\varepsilon_{\mathrm{ds} 1}}{\varepsilon_{\mathrm{f}} \xi_{\varepsilon}}\right)^{2}}\right] \mathrm{d} \varepsilon_{\mathrm{ds} 1}
$$

Where $\mathrm{e}_{\mathrm{f}}=$ strain in the ferrocement at maximum stress

$\mathrm{x}_{\sigma}=$ Stress softening coefficient for the ferrocement face

$\mathrm{x}_{\varepsilon}=$ Strain softening coefficient for the ferrocement face

$$
F_{c 1}=f_{c m}\left(1+0.13 S_{F}\right)
$$

$\mathrm{F}_{\mathrm{cl}}=$ compressive stress of the ferrocement,

$\mathrm{S}_{\mathrm{F}}=$ specific surface factor.

$\mathrm{f}_{\mathrm{cm}}=$ ferrocement compressive strength of mortar

$$
S_{F}=s \frac{f_{y}}{f_{c m}}
$$

$\mathrm{s}=$ specific surface area per volume

$$
\begin{gathered}
\xi_{\sigma}=\frac{0.85}{\sqrt{1+7.5 \sqrt{\varepsilon_{\mathrm{r} 1}}}} \\
\xi_{\varepsilon}=\frac{0.85}{\sqrt{1+18 \sqrt{\varepsilon_{\mathrm{r} 1}}}}
\end{gathered}
$$

d.) Tensile strength of mortar

$$
\sigma_{r 1}=\left\{\begin{array}{r}
\varepsilon_{r 1 \mathrm{E}_{\mathrm{m}}}, \varepsilon_{r 1} \leq \varepsilon_{\mathrm{cr}} \\
\left(1.06-500 \varepsilon_{r 1}\right) \mathrm{f}_{\mathrm{tm}}, \varepsilon_{r 1}>\varepsilon_{\mathrm{cr}}
\end{array}\right.
$$




\section{e.) Compression of concrete strut}

Taking the effect of tension softening in concrete, the compressive stress of concrete $\sigma_{\mathrm{d} 4}$ can be calculated as per the equations given below:

$$
\sigma_{\mathrm{d} 4}=\mathrm{k}_{4} \xi_{4} \mathrm{f}_{\mathrm{c} 4}
$$

where $\zeta_{4}=$ softening coefficient for the concrete face

$\mathrm{K}_{4}=$ ratio of average stress to the peak stress in the concrete stress block

$\mathrm{f}_{\mathrm{c} 4}=$ cylindrical compressive strength of concrete (Hsu,1988)

$$
\mathrm{K}_{4}=\frac{\varepsilon_{\mathrm{ds} 4}}{\varepsilon_{04}}\left(1-\frac{\varepsilon_{\mathrm{ds} 4}}{3 \varepsilon_{04}}\right)
$$

where $\mathrm{e}_{04}=$ strain in concrete at the peak stress $=-0.002$

The softening coefficient is to be changed for high-strength concrete as given by (Zhang and Hsu, 1998)

$$
\xi_{\sigma 4}=\xi_{\varepsilon 4}=\xi_{4}=\frac{5.8}{\sqrt{f_{c 4}} \sqrt{1+\frac{400 \epsilon_{r 4}}{\eta}}}
$$

where $\eta=$ ratio of the tensile force in the transverse steel to the tensile force in the longitudinal steel and, if greater than 1.0, it should be taken as a value of $1 / \eta$.

$f_{t m}=$ tensile strength of mortar

The number of unknowns and the number of available equations are 22 as shown in Tab. 1.

\section{ALGORITHM}

i. Take the surface compressive strains $\varepsilon_{\mathrm{d} 44}$ and $\varepsilon_{\mathrm{d} 4}$ at the centerline of the shear flow.

ii. Assume an initial value for $\xi_{4}$. iii. Calculate the ratio of the average stress to the peak stress $\mathrm{K}_{4}$ using Equation 34.

iv. if $\xi_{4}>1$, then make it $\xi_{4}=1$; calculate $\mathrm{e}_{\mathrm{p} 4}$ using Equation 35 .

v. Calculate $\mathrm{s}_{\mathrm{d} 4}$ using Equation 33.

vi. Assume a suitable value for $\mathrm{T}_{\mathrm{d} 4}$

vii. Assuming $\mathrm{e}_{\mathrm{t} 4}<\mathrm{e}_{\mathrm{ty}}$, calculate $\alpha_{4}$ using Equation 5, putting $\mathrm{F}_{\mathrm{t} 4}$ as per Equation 26.

viii. Calculate $e_{t 4}$ using Equation 13.

ix. If $\mathrm{e}_{\mathrm{t} 4} \geq \mathrm{e}_{\mathrm{ty} 4}$, recalculate $\alpha_{4}$ taking $\mathrm{f}_{\mathrm{t} 4}=\mathrm{F}_{\mathrm{ty} 4}$ in Equation 5 and $\mathrm{e}_{\mathrm{t} 4}$ using Equation 13

$x$. Assume a suitable value for $\mathrm{a}_{1}$

xi. Assume a suitable value for $\mathrm{T}_{\mathrm{d} 1}$.

xii. Calculate $\mathrm{e}_{\mathrm{ds} 1}$ using Equation 21.

xiii. Calculate $\mathrm{g}_{|t|}, \mathrm{g}_{|t|}$ using Equations 14 and 22 respectively, as $\mathrm{b}$ and $\mathrm{d}$ can be calculated.

xiv. Calculate $\mathrm{e}_{\mathrm{r} 1}$ from Equation 11.

$x v$. Calculate the stress and strain softening coefficient for the ferrocement face, i.e., $\mathrm{x}_{\sigma}, \mathrm{x}_{\varepsilon}$ by using Equations 30 and 31 respectively.

xvi. Calculate $\mathrm{s}_{\mathrm{d} 1}$ using Equation 27 by Simpson's rule and $\mathrm{s}_{\mathrm{r} 1}$ from Equation 32.

xvii. Calculate $\mathrm{e}_{\mathrm{d} 1}$ from Equation 19.

xviii. Calculate $e_{t 1}$ using Equation 10 .

xix. If $\mathrm{e}_{\mathrm{t} 1}<\mathrm{e}_{\mathrm{ty} 1}, \mathrm{~F}_{\mathrm{t} 1}=\mathrm{E}_{\mathrm{s}} \mathrm{e}_{\mathrm{t} 1}$, if $\mathrm{e}_{\mathrm{t} 1} \geq \mathrm{e}_{\mathrm{ty} 1}, \mathrm{~F}_{\mathrm{t} 1}=\mathrm{F}_{\mathrm{ty} 1}$ as per Equation 25.

$x x$. Calculate $\rho_{\mathrm{t} 1}$ using Equation 4 and the improved value of $\mathrm{T}_{\mathrm{d} 1}$ using formulae $\rho_{t 1}=\frac{A_{t 1}}{T_{d 1} s_{w}}$.

xxi. Check the assumed value of $T_{d 1}$ with the calculated value of $T_{d \text { limp }}$, if the error $1=\frac{T_{d 1}-T_{d \text { limp }}}{T_{d 1}} \times 100$ more than 1 , then improve the assumed value as below and start the calculation

\begin{tabular}{|c|c|c|c|c|c|c|c|c|c|c|}
\hline \multicolumn{11}{|c|}{ VARIABLES and EQUATIONS used for Solution } \\
\hline 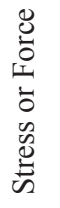 & 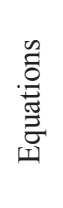 & 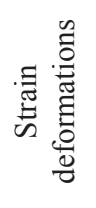 & 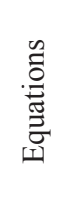 & 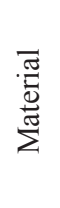 & $\frac{\tilde{0}}{\stackrel{0}{\tilde{Z}}}$ & 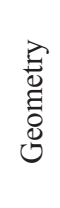 & 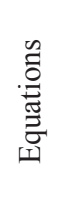 & 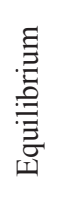 & 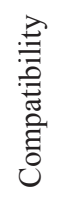 & 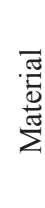 \\
\hline $\mathrm{s}_{\mathrm{d} 4}$ & 33 & $\mathrm{e}_{14}$ & 12 & $\mathrm{~K}_{4}$ & 34 & $\alpha_{4}$ & 5 & 2 & 9 & 23 \\
\hline $\mathrm{s}_{\mathrm{d} 1}$ & 27 & $e_{t 4}$ & 13 & $\xi_{4}$ & 3 & $a_{1}$ & 2 & 3 & 10 & 24 \\
\hline $\mathrm{S}_{\mathrm{r} 1}$ & 32 & $\mathrm{e}_{\mathrm{r} 4}$ & 35 & & & $\mathrm{~T}_{\mathrm{d} 1}$ & 4 & 4 & 11 & 25 \\
\hline $\mathrm{F}_{a}$ & 23 & $\mathrm{~g}_{1 \mathrm{t} 4}$ & 14 & & & $\mathrm{~T}_{\mathrm{d} 4}$ & 8 & 5 & 12 & 26 \\
\hline $\mathrm{F}_{\mathrm{A}}$ & 24 & $\mathrm{e}_{11}$ & 9 & & & & & 8 & 13 & 27 \\
\hline $\mathrm{F}_{\mathrm{t} 4}$ & 26 & $e_{t 1}$ & 10 & & & & & & 14 & 32 \\
\hline $\mathrm{F}_{\mathrm{t} 1}$ & 25 & $\mathrm{e}_{\mathrm{r} 1}$ & 11 & & & & & & 21 & 33 \\
\hline & & $\mathrm{g}_{\mathrm{It1}}$ & 22 & & & & & & 22 & 34 \\
\hline & & $\mathrm{e}_{\mathrm{d} 1}$ & 21 & & & & & & & 35 \\
\hline \multicolumn{7}{|c|}{ Total $=7+9+2+4=22$} & & \multicolumn{3}{|c|}{ Total $=5+8+9=22$} \\
\hline
\end{tabular}
from step $11, \mathrm{~T}_{\mathrm{d} 1}=\frac{\left(\mathrm{T}_{\mathrm{d} 1 \mathrm{imp}}+\mathrm{T}_{\mathrm{d} 1}\right)}{2}$.

Tab. 1 Variables and equations used for the torsion solution. 
xxii. Assuming $\mathrm{e}_{11}<\mathrm{e}_{1 \mathrm{y} 1}$, calculate the improved value of $\mathrm{a}_{1}$ using Equation 2, putting the value of $F_{11}$ from Equation 23 .

xxiii. Calculate $\mathrm{e}_{11}$ using Equation 9.

xxiv. Check if $\mathrm{e}_{11} \geq \mathrm{e}_{1 \mathrm{yl}}$, recalculate $\mathrm{a}_{1}$ using Equation 2 putting $\mathrm{F}_{11}=\mathrm{F}_{1 \mathrm{yl}}$ and check $\mathrm{e}_{11}$ by Equation 9 respectively.

$x x v$. Check the assumed value of $a_{1}$ and calculate the value of $a_{1}$. If error2 $=\frac{\alpha_{1}-\alpha_{\text {limp }}}{\alpha_{1}} \times 100$ more than unity, improve the assumed value of $\alpha_{1}=\left(\alpha_{1}+\alpha_{\text {limp }}\right) / 2$ and start the calculations again from step 10

xxvi. Calculate $\mathrm{T}_{\mathrm{d} 4}$ using Equation 8 .

xxvii. Check the assumed value of $T_{d 4}$ and calculate the value of $T_{d 4}$ If error $3=\frac{T_{d 4}-T_{d 4 i m p}}{T 4} \times 100$ is greater than unity, improve the assumed value of $\mathrm{T}_{\mathrm{d} 4}=\frac{\left(\mathrm{T}_{\mathrm{d} 4 \mathrm{imp}}+\mathrm{T}_{\mathrm{d} 4}\right)}{2}$ and start the calculations again from step 6 .

xxviii. Calculate $e_{14}$ by using Equation 12.

xxix. Calculate $\sigma_{\mathrm{d} 4}$ from Equation 3 taking $\mathrm{F}_{14}$ from Equation 24.

$x x x$. Calculate $\xi_{\text {4imp }}$ from Equation 33.

xxxi. If $\xi_{\text {4imp }}>1.0$, then make $\xi_{4 \text { imp }}=1.0$

xxxii. If error $4=\frac{\xi_{4}-\xi_{4 i m p}}{\xi_{4}} \times 100$ is more than 1 , start from step 2

by making $\xi_{4}=\frac{\left(\xi_{\text {4imp }}+\xi_{4}\right)}{2}$ xxxiii. Calculate $\mathrm{q}, \gamma_{1+1}$ and $\gamma_{1 t 4}$ by using Equations 7, 11 and 14 respectively.

xxxiv. Calculate the torque T using Equation 1 and the corresponding value $\theta$ by Equation 21 in the post-cracking range.

xxxv. Choose another value of $\varepsilon_{\mathrm{ds} 4}$. Find out the torque and twist. Repeat from step 1 till either of the matrix strains $\varepsilon_{\mathrm{ds} 4}$ reaches the failure strain or the steel strains reach the yield strain.

\section{VALIDATION OF THE PROPOSED MODEL}

For the validation of the proposed model, beams were cast and tested. Experimental and analytical torque twist diagrams were presented to verify the accuracy of the model. To study the effect of the arrangement of the reinforcement on the torque twist response, six possible cases of the arrangement of the reinforcement were considered, keeping the number of mesh layers as four, the ferrocement matrix strength of $55 \mathrm{MPa}$, the core concrete strength of $60 \mathrm{MPa}$ and the aspect ratio of 2 constant. The reinforcement can be arranged in six ways (Rao and Seshu, 2003), i.e. either a) in a longitudinal direction, b) a transverse direction, c) under-reinforced in both the longitudinal and transverse directions, d) longitudinally over reinforced and transversely under reinforced, e) longitudinally under reinforced and transversely over reinforced and, f) completely over-reinforced in both directions.

Tab. 2 Details of Beams Tested, Mesh wire diameter $=0.72 \mathrm{~mm}$.

\begin{tabular}{|c|c|c|c|c|c|c|c|c|c|c|}
\hline & \multirow{4}{*}{ Series } & \multirow{4}{*}{ 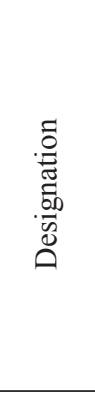 } & \multirow{4}{*}{ 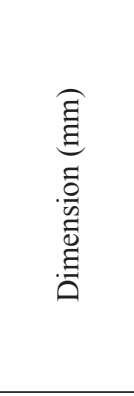 } & \multirow{2}{*}{\multicolumn{2}{|c|}{ Compressive strength }} & \multicolumn{5}{|c|}{ Reinforcement Details } \\
\hline & & & & & & \multicolumn{4}{|c|}{ Core Reinforced Concrete } & \multirow{3}{*}{ 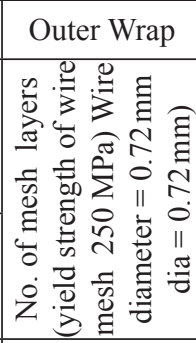 } \\
\hline & & & & \multirow{2}{*}{ 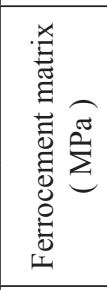 } & \multirow{2}{*}{ 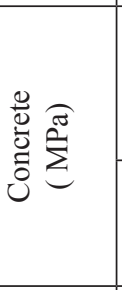 } & \multicolumn{2}{|c|}{ Longitudinal Steel } & \multicolumn{2}{|c|}{ Transverse steel } & \\
\hline & & & & & & $\begin{array}{l}\text { Diameter, } \\
\text { No. of bars }\end{array}$ & $\begin{array}{c}\text { Yield } \\
\text { Strength } \\
(\mathrm{MPa})\end{array}$ & $\begin{array}{l}\text { Diameter, } \\
\text { Spacing }\end{array}$ & $\begin{array}{c}\text { Yield } \\
\text { Strength } \\
(\mathrm{MPa})\end{array}$ & \\
\hline 1 & \multirow{2}{*}{ Plain Beams } & $\mathrm{BH}$ & $125 \times 250$ & 55 & & & & & & 0 \\
\hline 2 & & $\mathrm{~B} 4 \mathrm{H}$ & $125 \times 250$ & 55 & 60 & & & & & 4 \\
\hline 3 & Only Longitudinal & $\mathrm{L} 4 \mathrm{H}$ & $125 \times 250$ & 55 & 60 & $\begin{array}{c}12 \mathrm{~mm}, \\
6 \mathrm{nos} .\end{array}$ & 440 & & & 4 \\
\hline 4 & Only Transverse & $\mathrm{T} 4 \mathrm{H}$ & $125 \times 250$ & 55 & 60 & & & $\begin{array}{c}10 \mathrm{~mm} @ \\
70 \mathrm{~mm} \mathrm{c} / \mathrm{c}\end{array}$ & 445 & 4 \\
\hline 5 & \begin{tabular}{|c|} 
Torsionally under rein- \\
forced in Longitudinal and \\
transverse direction \\
\end{tabular} & $\mathrm{U} 4 \mathrm{H}$ & $125 \times 250$ & 55 & 60 & $\begin{array}{l}6 \mathrm{~mm}, \\
6 \mathrm{nos} .\end{array}$ & 350 & $\begin{array}{c}6 \mathrm{~mm} @ \\
70 \mathrm{~mm} \mathrm{c} / \mathrm{c}\end{array}$ & 350 & 4 \\
\hline 6 & \begin{tabular}{|} 
Torsionally Over rein- \\
forced in Longitudinal \\
direction and Under \\
Reinforced in transverse \\
direction
\end{tabular} & $\mathrm{Lo} 4 \mathrm{H}$ & $125 \times 250$ & 55 & 60 & $\begin{array}{c}12 \mathrm{~mm}, \\
6 \mathrm{nos} .\end{array}$ & 440 & $\begin{array}{c}6 \mathrm{~mm} @ \\
70 \mathrm{~mm} \mathrm{c} / \mathrm{c}\end{array}$ & 350 & 4 \\
\hline 7 & $\begin{array}{c}\text { Torsionally under rein- } \\
\text { forced in Longitudinal di- } \\
\text { rection and over reinforced } \\
\text { in transverse direction }\end{array}$ & To4H & $125 \times 250$ & 55 & 60 & $\begin{array}{l}6 \mathrm{~mm}, \\
6 \mathrm{nos} .\end{array}$ & 350 & $\begin{array}{c}10 \mathrm{~mm} @ \\
70 \mathrm{~mm} \mathrm{c} / \mathrm{c}\end{array}$ & 445 & 4 \\
\hline 8 & $\begin{array}{c}\text { Torsionally over rein- } \\
\text { forced in Longitudinal and } \\
\text { transverse directions }\end{array}$ & $\mathrm{Co} 4 \mathrm{H}$ & $125 \times 250$ & 55 & 60 & $\begin{array}{c}12 \mathrm{~mm}, \\
6 \mathrm{nos} .\end{array}$ & 440 & $\begin{array}{c}10 \mathrm{~mm} @ \\
70 \mathrm{~mm} \mathrm{c} / \mathrm{c}\end{array}$ & 445 & 4 \\
\hline
\end{tabular}


The RC beam details are given in Table 2. In members under torsional loads, diagonal cracks are formed in the shape of a helix. To allow two complete spirals in the central test region of the test beam, a length of $1500 \mathrm{~mm}$ was kept for observation of the crack pattern. In order to force the failure in the central portion of the beam, the end zones of a length of $250 \mathrm{~mm}$ were heavily reinforced. Thus the total length of the beam was fixed as $2000 \mathrm{~mm}$ for the aspect ratio 2.0 for the beam size $(125 \mathrm{~mm} \mathrm{X} 250 \mathrm{~mm})$. A control specimen, BH, of plain concrete without any reinforcement in its core was cast. Another control specimen, $\mathrm{B} 4 \mathrm{H}$, of the same size without any reinforcement in the core was cast with $25 \mathrm{~mm}$ thick ferrocement " $U$ " wraps containing four mesh layers.

\subsubsection{Material and Material Properties}

a) Cement: Ordinary 53 grade Portland cement conforming to Indian Standard (IS: 12269, 1987) was used throughout the experimental program. The standard consistency was $28 \%$, whereas the initial and final setting time was $95 \mathrm{~min}$. and 210 min. respectively. The specific gravity of the cement was 3.14 , and its compressive strength after 28 days was $57 \mathrm{MPa}$.

b) Coarse Aggregate: Crushed hard granite stone of a maximum size of $20 \mathrm{~mm}$ was used for the concrete. The bulk density of the aggregate was $1695 \mathrm{~kg} / \mathrm{m}^{3}$, and the specific gravity was found to be 2.65 .

c) Fine Aggregate: The International Ferrocement Information Centre (IFIC) model code (2001) suggests that the size of the sand particle in a ferrocement matrix should not be more than one half of the size of the opening of the mesh. The mesh opening was $6.35 \mathrm{~mm}$. River sand that passed through a $1.18 \mathrm{~mm}$ sieve was used in the ferrocement matrix's preparation. The specific gravity of the sand was 2.65 . The fine aggregate used in this investigation for the concrete was river sand conforming to Zone-II of (IS: 383,1970 ). The fineness modulus was 2.81 .

d) Wire meshes: Square woven wire meshes made of galvanized steel were used for the " $U$ " wraps. The diameter of the wire was $0.72 \mathrm{~mm}$, and the yield strength was $250 \mathrm{~N} / \mathrm{mm}^{2}$; the centre-to-centre spacing of the wires was $6.35 \mathrm{~mm}$.

e) Reinforcement: 6,10 and $12 \mathrm{~mm}$ diameter bars were used in the entire experimental study. The yield stresses of these bars were $350 \mathrm{~N} / \mathrm{mm}^{2}, 440 \mathrm{~N} / \mathrm{mm}^{2}$ and $440 \mathrm{~N} / \mathrm{mm}^{2}$ respectively.

\subsubsection{Casting of the Specimen}

a) Preparation of the mesh layer: The required length of the mesh layer was cut from a $1200 \mathrm{~mm}$-wide mesh roll up to a length of $1980 \mathrm{~mm}$ and bent to the desired shape. All the layers required for the beam were prepared in the same manner and arranged one above the other. The layers were separated by smaller diameter spacer bars.

b) Preparation of the End Cage: To avoid failure in the end regions, the ends were heavily reinforced, but care was taken to avoid congestion of the reinforcement.

c) Casting: The "U" shaped mesh layers were properly put in the mould. The sides of the mesh layers were separated by spacer bars to provide proper gaps. The ferrocement matrix, which was properly mixed in the mixture machine, was put in the mould up to a depth of approximately $25 \mathrm{~mm}$. A closed wooden box of the size of the concrete core was put in the mould, and the ferrocement matrix was poured from the top to fill up the portions of the wrappings. Within the elapsed initial setting time of the ferrocement matrix, the hollow box section was carefully removed. The end cage reinforcements and the reinforcement in the core portion were put in their proper place. The filled concrete was vibrated. After 24 hours, the mould was carefully removed along with its companion and put in the curing tank.

\subsubsection{Testing}

The beams were tested on a torsion test rig available in the laboratory. The marked beams were mounted on the wing table of a Tinius-Olsen testing machine. Rollers in the lateral direction at the reaction end were provided to allow the beam to slide freely along the longitudinal direction to avoid any axial restraint. The loading end was supported on a cylindrical roller placed in the longitudinal direction of the beams to allow a twist under pure torsion. This set up is shown in (Fig. 5). Specially made steel trusses were used as lever arms and placed at both supports to apply transverse loads, which in turn produced torsion on the member. The load was gradually applied through a mechanical jack. The dial gauge readings attached to the twist meters were recorded for each increment of load. The load at the first crack was noted, and then the cracks formed for each increment of the load were marked along with the crack marker. The peak load was recorded.

\subsection{Discussion of the Torsional Behaviour of the HSC Beams}

The torsional behaviour of the high-strength concrete beams with a core and without a core reinforcement were studied separately.

\subsubsection{Torsional Behaviour of Unreinforced HSC beams}

The first crack for the unreinforced high-strength concrete beam (BH) appeared on the longer face; on a further attempt to load, the failure of the beam resulted in cracks connecting each face at $45^{\circ}$ as spirals, the same as noticed by (Hsu, 1984). This is due to the fact that the shear stress induced is more than the shear strength of the material provided on that face. The failure of the $\mathrm{BH}$ beam was catastrophic, as it suddenly failed with the appearance of a crack on the longer face and was connected spirally. The crack on the B4H beam wrapped with a ferrocement "U" wrap appeared on the unwrapped concrete's shorter face. The beams that failed with a single potential crack appeared on the top of the un-wrapped concrete face in a similar manner as observed in normal strength concrete beams (Behera et al., 2010). The failure plane changed from the longer face to the shorter un-wrapped face in the case of B4H due to the higher shear resistance provided by the ferrocement shell on the longer face. The ultimate failure of these two beams was found to be due to the formation of a single potential crack with an inclination of approximately $45^{\circ}$ to the longitudinal axis. The BH beam failed with a torque of $4.612 \mathrm{kNm}$, while the B4H beam failed with a torque of $6.50 \mathrm{kNm}$. The experimental torque-twist diagram of the ferrocement " $U$ " wrapped plain high-strength beam plotted is in (Fig. 6). The torque varies linearly with the twist, and the linearity ends once the torque is more than the elastic torque. This is because of the formation of micro-cracking in the ferrocement portion. The micro cracking region ends when the visible crack appears on the surface.

\section{Ultimate Torque and Crack Angle}

The ultimate torque and twist were found to be $4.61 \mathrm{kNm}$ and $0.0028 \mathrm{rad} / \mathrm{m}$ for the BH beam respectively. The same as calculated by 
Tab. 3 Experimental and theoretical values of the torsional parameters.

\begin{tabular}{|c|c|c|c|c|c|c|c|c|}
\hline \multirow{2}{*}{$\begin{array}{c}\text { Beam } \\
\text { designation }\end{array}$} & \multicolumn{3}{|c|}{ Torsional stiffness $\quad\left(\mathrm{kN}-\mathrm{m}^{2}\right)$} & \multicolumn{2}{|c|}{ Torque (kN-m) } & \multirow{2}{*}{$\begin{array}{l}\text { Toughness } \\
(\mathrm{kN}-\mathrm{m} / \mathrm{m})\end{array}$} & \multicolumn{2}{|c|}{ Twist (rad/m) } \\
\hline & Initial & Cracking & Ultimate & Cracking & Ultimate & & Ultimate & Breaking \\
\hline BH (Expt) & 2108 & & & 4.612 & & & & 0.0028 \\
\hline B4H (Expt.) & 1750 & 1145 & & 6.500 & & 0.0219 & & 0.00546 \\
\hline L4H (Expt) & 1686 & 1167 & 869.3982 & 6.79 & 6.71 & 0.038 & 0.005818 & 0.00781 \\
\hline L4H (Analytical) & \multicolumn{8}{|c|}{ The model cannot predict the torsional capacity as the beam lacks one transverse reinforcement } \\
\hline T4H (Expt) & 1686 & 1153 & 915.2778 & 6.59 & 6.59 & 0.03317 & 0.00569 & 0.0072 \\
\hline T4H (Analytical) & \multicolumn{8}{|c|}{ The model cannot predict the torsional capacity as the beam lacks one longitudinal reinforcement } \\
\hline $\mathrm{U} 4 \mathrm{H}(\mathrm{Expt})$ & 1634 & 1188 & 38 & 6.4248 & 7.68 & 1.1441 & 0.1305 & 0.1945 \\
\hline U4H (Analytical) & 1626 & 1188 & 38 & 6.52 & 7.729 & 1.1550 & 0.13736 & 0.197 \\
\hline Lo4H(Expt) & 1721 & 1239 & 68 & 6.675 & 7.87 & 0.4258 & 0.056 & 0.0875 \\
\hline Lo4H (Analytical) & 1627 & 1250 & 66 & 6.52 & 7.8288 & 0.4185 & 0.0055 & 0.0873 \\
\hline To4H(Expt) & 1636 & 1225 & 72 & 6.618 & 8.66 & 0.7840 & 0.0921 & 0.1124 \\
\hline To4H (Analytical) & 1627 & 1226 & 72.75 & 6.52 & 8.58 & 0.7821 & 0.0921 & 0.1116 \\
\hline $\mathrm{Co} 4 \mathrm{H}(\mathrm{Expt})$ & 1662 & 1242 & 130 & 6.7163 & 12.91 & 0.8121 & 0.0754 & 0.092 \\
\hline Co4H (Analytical) & 1627 & 1289 & 129 & 6.52 & 12.98 & 0.8016 & 0.074 & 0.0929 \\
\hline
\end{tabular}

the skew bending theory was found be $4.34 \mathrm{kNm}$ and $0.003468 \mathrm{rad} / \mathrm{m}$. When a similar beam was provided with ferrocement "U" wraps with four layers of mesh and even with a ferrocement matrix of a lower strength ( $55 \mathrm{MPa})$ than that of the core concrete, the torsional strength was found to be $6.50 \mathrm{kNm}$ versus the theoretical value of $6.52 \mathrm{kNm}$.

This shows that beams with " $U$ " wraps have more strength than that of plain beams and that their strength cannot be estimated by the skew bending theory. The enhancement may be due to the prestressing effect of the "U" wrap (Panchacharam and Belarbi, 2002). The twist at the ultimate torque of the $\mathrm{B} 4 \mathrm{H}$ beam was predicted by the theoretical model as $0.0056 \mathrm{rad} / \mathrm{m}$ versus the experimental values of $0.0055 \mathrm{rad} / \mathrm{m}$. The theoretical crack angle for the concrete and ferrocement face should be $45^{\circ}$. The reason is due to the equal volume fraction of the reinforcement in both directions. The experimental crack angles for the wrapped ferrocement face and concrete were $46.17^{\circ}$ and $45^{\circ}$ respectively. The initial stiffness of the B4H was found to be $1626 \mathrm{kNm}^{2}$. The twist up to the elastic torque depends on torsional rigidity and is independent of the face (wrapped or un- wrapped) of the cracking, but at the ultimate torque, the twist is dependent on the face of the initiation of the formation of the crack, as the cracks on the wrapped faces allow the beams to rotate more, thereby providing better ductility. The toughness of the B4H beam was found to be $0.0219 \mathrm{kNm} / \mathrm{m}$.

\subsubsection{Torsional Behaviour of Ferrocement "U" Wrapped High-Strength RC Beams}

The reinforcement is activated after cracking. So, the torquetwist response of a RC beam beyond cracking is influenced by the reinforcement present in the beam. The post-cracking torque-twist response of a ferrocement " $U$ " wrapped beam is characterized by the reinforcement present in the core concrete and the mesh layers in the ferrocement shell. After the cracking, torsional resistance is offered by the longitudinal reinforcement, the transverse reinforcement, the ferrocement on three faces, and the concrete present between the

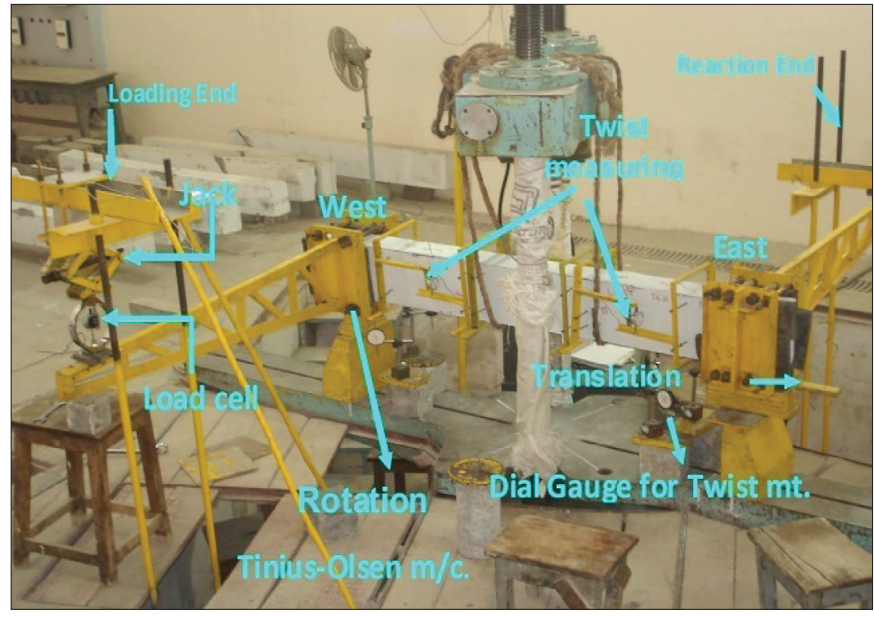

Fig. 5 Torsion test set up.
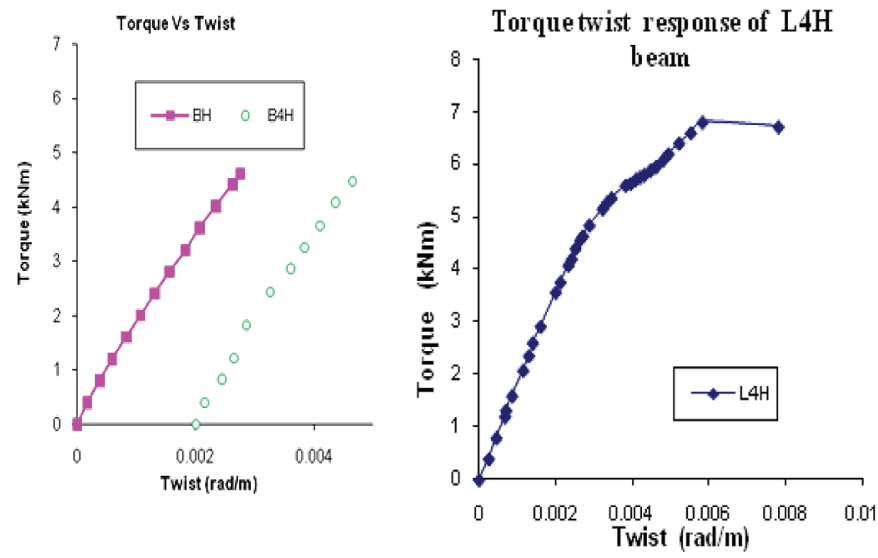

Fig. 6 Torque twist response of $B H \& B 4 H$. 


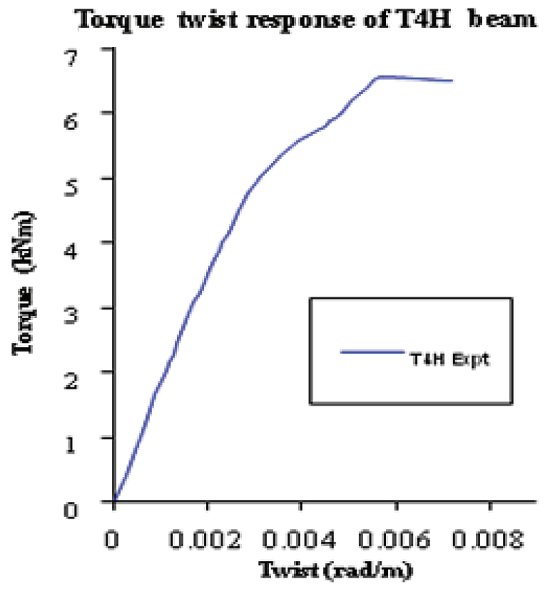

Fig. 8 Torque twist response of $T 4 H$.

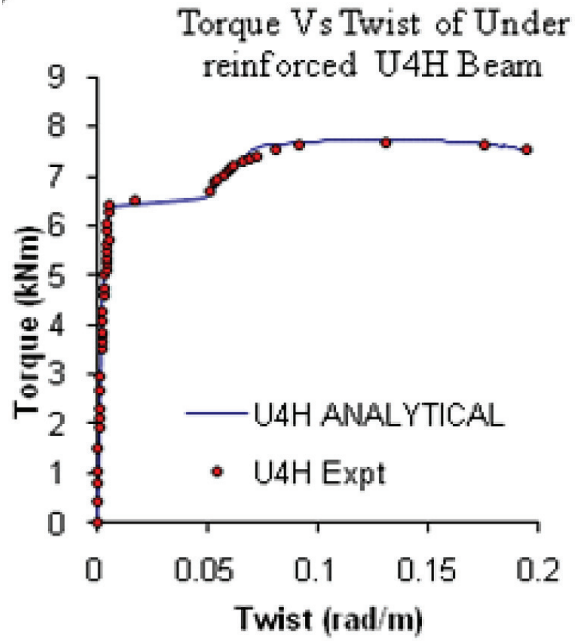

Fig. 9 Torque twist response of $U 4 H$.

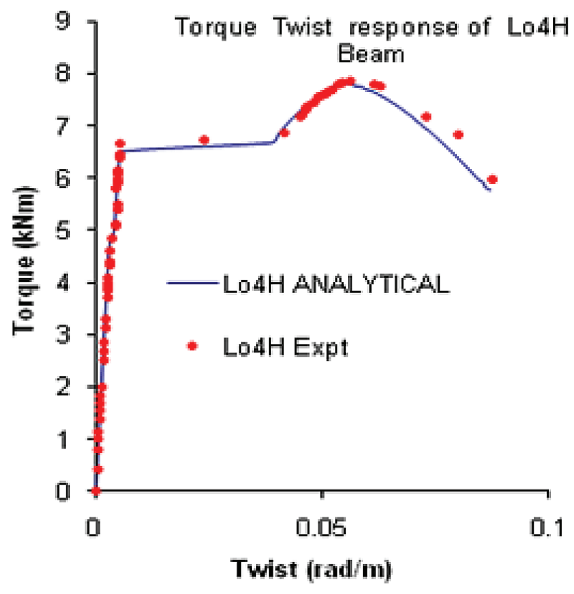

Fig. 10 Torque twist response of Lo4H. diagonal struts. As the first two categories lack one of the resisting components, they can be analyzed as plain beams with "U" wraps.

\section{Beams with only Longitudinal Reinforcement}

The L4H beam was cast with six 12- mm diameter bars as longitudinal reinforcements and without any transverse reinforcement with four mesh layers in the ferrocement shell.

a) Torque: The cracking and ultimate torque of the $\mathrm{L} 4 \mathrm{H}$ beam was found to be $6.79 \mathrm{kNm}$. The increase in the torque of the L4H beam over its plain "U" wrap B4H beam is $4.46 \%$. The torque-twist response as shown in (Fig.7) shows that only the behaviour of the longitudinally reinforced beam was similar to the plain wrapped beam. The first crack was initiated on the unwrapped face of the beam. The $\mathrm{L} 4 \mathrm{H}$ beam was a replica of the $\mathrm{B} 4 \mathrm{H}$, having only longitudinal reinforcement in the core area. The cause of the initiation of the first crack in the unwrapped face was due to the induced shear stress, which is more than the shear capacity of the material in the core area.

b) Twist: There was an increase in the twist at the ultimate torque with respect to its plain $\mathrm{B} 4 \mathrm{H}$ beam. The twist at the ultimate torque was found to be $0.0078 \mathrm{rad} / \mathrm{m}$. The increase in the twist over the plain "U" wrapped B4H beam was found to be $39.28 \%$. c) Stiffness: The initial stiffness of a beam is independent of its reinforcement. The initial stiffness of the $\mathrm{L} 4 \mathrm{H}$ beam was found to be $1686 \mathrm{kNm}^{2}$.

d) Toughness: Toughness is measured as the area under the torque twist curve. The increase in the twist enhances the toughness of the beam over the plain "U" wrapped beam. The toughness of the beam was found to be $0.038 \mathrm{kNm} / \mathrm{m}$ with an increase of $73.5 \%$ over the plain "U" wrap B4H beam.

\section{Beams with only Transverse Reinforcement}

To investigate the effect of only transverse reinforcement, the $\mathrm{T} 4 \mathrm{H}$ beam was cast and tested. T4H was cast with stirrups of $10 \mathrm{~mm}$ diameter bars at a spacing of $70 \mathrm{~mm} \mathrm{c} / \mathrm{c}$ without any longitudinal reinforcement in the test region. The first crack appeared on the unwrapped face of the beam. There was no such improvement in the cracking torque of $\mathrm{T} 4 \mathrm{H}$ over the plain $\mathrm{B} 4 \mathrm{H}$ beam as shown in (Fig. 8).

a) Torque: The cracking and ultimate torque of the beam was found to be $6.59 \mathrm{kNm}$. The increase in the cracking torque over the B4H beam was only $1.38 \%$

b) Twist: After the formation of the first crack, the beam was unable to resist a further load, but twisted continuously under the constant ultimate loading. The twist at the cracking of the

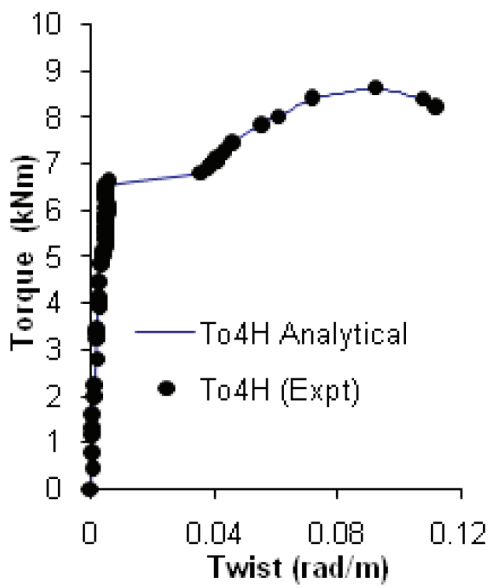

Fig. 11 Torque twist response of To4H.

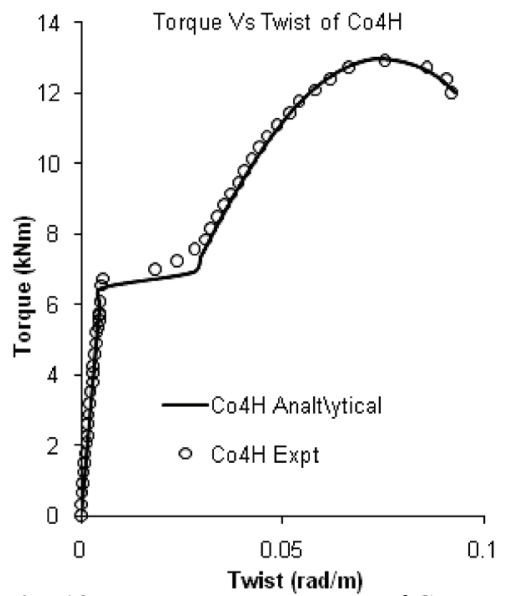

Fig. 12 Torque twist response of $\mathrm{Co} 4 \mathrm{H}$.

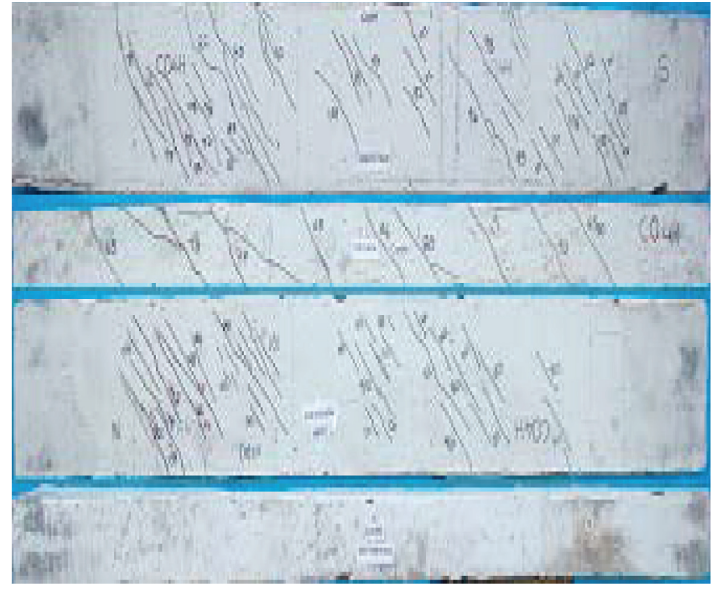

Fig. 13 Crack pattern of Co4H. 


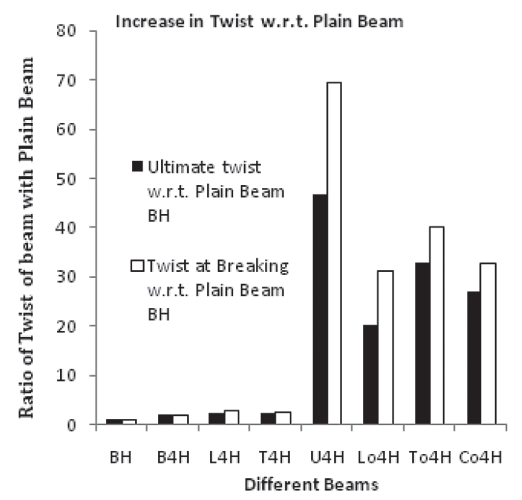

Fig. 14 Percentage increase in torque w.r.t. plain beam.

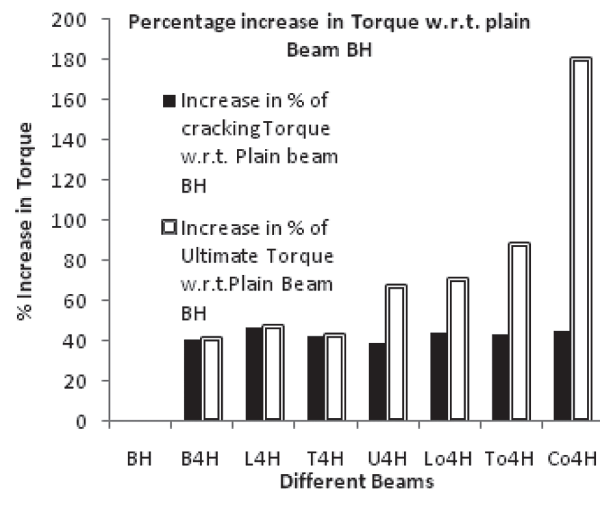

Fig. 15 Increase twist w.r.t. plain beam.

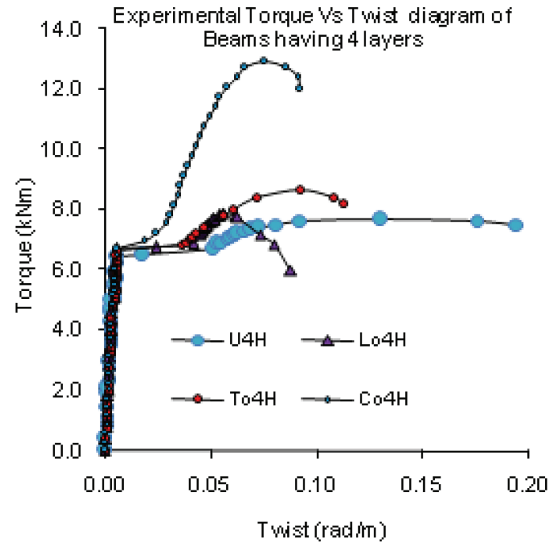

Fig. 16 Experimental torque twist responses of different states of torsion. beam was found to be $0.0056 \mathrm{rad} / \mathrm{m}$ and the twist at the ultimate torque of $0.0072 \mathrm{rad} / \mathrm{m}$. The increase in the ultimate twist over the cracking twist was found to be $28.57 \%$.

c) Stiffness: The initial stiffness of the T4H beam was found to be $1686 \mathrm{kNm}^{2}$ over the predicted value of $1626 \mathrm{kNm}^{2}$.

d) Toughness: The toughness of the beam was found to increase $51.14 \%$ over the plain beam.

A single type of reinforcement could not improve the torsional strength of the ferrocement "U" wrapped beams, but was capable of increasing their toughness.

\section{General Behaviour of RC High-Strength Beams}

All the beams were replicas of B4H with different amounts of reinforcement in the core concrete. As the initiation of the crack for the $\mathrm{B} 4 \mathrm{H}$ beam was on an unwrapped face, as in all the reinforced concrete beams, the first crack was found on an unwrapped concrete face. Small segmental cracks were developed with subsequent torsional loading on the wrapped and unwrapped faces. The formation of cracks ceased before the ultimate loading and widening of the cracks took place on the unwrapped face, while there was the formation of still new cracks on the wrapped faces. The cracks on the different faces connected before failure. Beyond the ultimate torque, all the beams showed a drooping portion. The four beams provided with both longitudinal and transverse reinforcements showed a considerable amount of increase in their torsional strength beyond the cracking torque. The ultimate torque was found to be increasing in an order from the under reinforced, longitudinally over reinforced, transversely over reinforced to completely over reinforced categories. The experimental and theoretical torque twist response of the under reinforced, longitudinally over reinforced, transversely over reinforced and completely over reinforced beams are presented in (Figs. $9,10,11$ and 12) respectively. The torque-twist diagram was linear up to the elastic torque after which there was deviation in the linearity. The change of linearity can be seen from the cracking as during the micro-cracking, any deviation is not prominent.

\section{Crack Pattern, Torque, Twist and Stiffness}

The first crack appeared on the unwrapped face in each beam. The cracks were formed in the unwrapped concrete face as well as the wrapped ferrocement faces. The crack angles were found to vary from $40.96^{\circ}$ to $47.54^{\circ}$ for the concrete face experimentally against the predicted values of $36.31^{\circ}$ to $48.75^{\circ}$ for the reinforced beams from the under reinforced state to the completely over reinforced state. The variation of the crack angle was found experimentally from $41.63^{\circ}$ to $56.78^{\circ}$ for the ferrocement faces against the predicted values of $43.90^{\circ}$ to $60.03^{\circ}$. The crack pattern for the Co4H beam was shown in Fig. 13 .

The cracking torque was found to increase with the increase in the amount of reinforcement, particularly with the longitudinal reinforcement. At the cracking, the twist was found to be increasing at a constant cracking torque. Thereafter, the torque and twist were increasing up to the ultimate torque. With the increase in the torque beyond the cracking, the cracks were formed in the ferrocement jacketed longer faces. The experimental initial stiffness, secant stiffness at the cracking torque and the secant stiffness at the ultimate torque values, the cracking and the ultimate torques are reported in Table 3 . The same values using the analytical model are presented in the same Table 3. The initial stiffness of these beams was found to be invariable, but the secant stiffness at the cracking and the secant stiffness at the ultimate torque were found to vary with the state of torsion. There was a maximum decrease in the post-cracking torsional stiffness for the under-reinforced beams provided with a fewer number of mesh layers on the ferrocement face. The ultimate torque calculated by using the proposed model was compared with respect to the "U" wrapped plain beams with the same number of mesh layers. The ultimate torque was found to increase from the under reinforced to the longitudinally over reinforced, transversely over reinforced, and completely over reinforced beams. There was a significant improvement in the ultimate torque with the variations in the state of torsion. The ultimate cracking torques of the $\mathrm{U} 4 \mathrm{H}, \mathrm{Lo} 4 \mathrm{H}$, To4H and $\mathrm{Co} 4 \mathrm{H}$ were experimentally found to be $6.42 \mathrm{kNm}, 6.675 \mathrm{kNm}, 6.618 \mathrm{kNm}$ and $6.71 \mathrm{kNm}$ against the predicted values of $6.52 \mathrm{kNm}$. The theory underestimates the cracking torque by $2.28 \%, 1.36 \%$ and $2.83 \%$ for the $\mathrm{Lo} 4 \mathrm{H}$, To $4 \mathrm{H}$ and $\mathrm{Co} 4 \mathrm{H}$ beams respectively, while it overestimates by $1.5 \%$ for the $\mathrm{U} 4 \mathrm{H}$. The ultimate torque of these beams were experimentally found to be $7.68 \mathrm{kNm}, 7.87 \mathrm{kNm}, 8.66 \mathrm{kNm}$ and $12.91 \mathrm{kNm}$ for the $\mathrm{U} 4 \mathrm{H}$, Lo4H, To4H and Co4H beams respectively. The predicted values of the ultimate torques were found to vary within $1 \%$ of the experimental values. The cracking torque of the $\mathrm{B} 4 \mathrm{H}, \mathrm{L} 4 \mathrm{~h}, \mathrm{~T} 4 \mathrm{H}, \mathrm{U} 4 \mathrm{H}, \mathrm{Lo} 4 \mathrm{H}$, To $4 \mathrm{H}$ and $\mathrm{Co} 4 \mathrm{H}$ was increased by $40.93 \%, 47.22 \%, 42.89 \%, 39.30 \%$, $44.73 \%, 43.50 \%$ and $45.62 \%$ with respect to the plain BH beam respectively, whereas the ultimate torque of these beams was increased to $40.94 \%, 47.22 \%, 42.89 \%, 66.52 \%, 70.64 \%, 87.77 \%$ and $179.92 \%$ respectively as shown in (Fig.14).The twist at the ultimate torque of these $\mathrm{U} 4 \mathrm{H}, \mathrm{Lo} 4 \mathrm{H}, \mathrm{To} 4 \mathrm{H}$ and $\mathrm{Co} 4 \mathrm{H}$ beams was found to vary by $0.1305 \mathrm{rad} / \mathrm{m}, 0.056 \mathrm{rad} / \mathrm{m}, 0.0921 \mathrm{rad} / \mathrm{m}$ and $\quad 0.0754 \mathrm{rad} / \mathrm{m} \mathrm{respec}-$ tively. The predicted values were found to be more than $4.98 \%$ for the $\mathrm{U} 4 \mathrm{H}$ and less than $1.78 \%, 0.6 \%$ and $2.4 \%$ for the Lo4H, To4H and $\mathrm{Co} 4 \mathrm{H}$ respectively. The twist at the breaking was reported in (Tab. 3), 
and the ratio of the twist of a beam with respect to the plain $\mathrm{BH}$ beam is presented in (Fig. 15).

The toughness of the beams was found to be the maximum for the under-reinforced beams as it allows the beams to twist more due to the less torsional stiffness. The To4H beam has more toughness in comparison to the Lo4H beam. When the number of layers is changed in the ferrocement wrap, it is found that toughness is increasing in the analytical model, but this increase is marginal. The variations of the torque were more prominent in the various states of torsion. The variations in the torque for the various states of torsion are presented in (Fig. 16).

\section{CONCLUSIONS}

- RC beams strengthened with ferrocement "U" wraps exhibit a significant increase in cracking torque, ultimate torque and ultimate twist when tested under pure torsion.
- The torsional strength of under-reinforced, partially over-reinforced and completely over-reinforced sections can be well predicted by this developed model.

- The equations developed are not only able to predict the torsional strength of "U" wrap beams, but can also predict the twists and strains in steel and concrete throughout their entire loading history.

- The developed model can well predict the torsional strength of "U" wrapped beams strengthened with any material other than ferrocement with suitable modifications in the material properties.

- The proposed equations well predict the ultimate torsional moments very closely to the experimental results.

- The experimental results reveal that the torque twist response of a ferrocement "U" wrap beam is more influenced by the state of torsion than the amount of ferrocement reinforcement. 


\section{REFERENCES}

American Concrete Institute (ACI) Committee 549. (1997) Ferrocement-Materials and Applications. In: ACI Symposium Proceedings SP-61: Farmington Hills, Michigan.

Adrian, K.Y.Hii. - Riadh, A.M. (2006) An experimental and numerical investigation on torsional strengthening of solid and box-section RC beams using CFRP laminates. Composite structures, 75 , 2006, pp. 213-221.

Adrian, K.Y.Hii. - Riadh, A.M. (2007) Torsional capacity of CFRP Strengthened reinforced concrete beams. Journal of Composites for Construction ASCE, Jan. Feb, pp. 71-80.

Behera, G.C. - Rao, T.D.G. - Rao, C.B.K. (2008) Torsional Capacity of High Strength Concrete Beams jacketed with ferrocement $U$ wraps. Asian Journal of Civil Engineering, Vol. 9, No. 4, pp. 411-422.

Behera, G.C. - Rao, T.D.G. - Rao, C.B.K. (2010) Torsional Strength of " $U$ " wrapped plain concrete sections. Indian Concrete Institute Journal, Vol. 11, No. 2, pp. 13-20.

Ghobarah, A. - Ghorbel, M.N. - Chidiaac, S.E. (2002) Upgrading Torsional Resistance of Reinforced Concrete Beams Using Fiber-Reinforced Polymer. Journal of Composites for Construction, Vol. 6, No. 4, pp. 257-263.

Hsu, T.T.C. (1984) Torsion of reinforced concrete, Von Nostrand Reinhold Co., New York.

Hsu, T.T.C. (1988) Softened truss model theory for shear and torsion. ACI Structural Journal, pp. 624-635.

IFS committee 10 (2001) Ferrocement model code. International Ferrocement society, AIT, Bangkok.

IS: 383-1970 (1970) Specifications for Coarse and Fine Aggregates from Natural Sources for Concrete.(Second Revision). Bureau of Indian Standards, Manak Bhavan, Bahadurshah Zafar Marg, New Delhi.

IS: 12269 (1987) Specification for 53 Grade ordinary Portland cement. Bureau of Indian Standards, Manak Bhavan, Bahadurshah Zafar Marg, New Delhi.
Leu, L.J. - Lee, Y.S. (2000) Torsion design charts for reinforced concrete rectangular members. Journal of Structural Division, ASCE, pp. 210 - 218.

Zhang, L.X. - Hsu, T.T.C. (1998) Behavior and analysis of 100MPa concrete membrane elements. ASCE, Journal of Structural Engineering, pp. 24-34.

Mansur, M.A. - Abdullah (1998) Constitutive laws of ferrocement under biaxial tension-compression. Journal of Ferrocement, pp. 285-293.

Mehran, A. - Harid, R. (2007) Analytical model for evaluating torque of FRP strengthened reinforced concrete beams. Journal of Composites for Construction, pp. 384-390.

Bansal, P.P. - Kumar, M. - Kaushik, S.K. (2007) Effect of mesh orientation on strength of beams retrofitted using ferrocement jacket. International Journal of Engineering, Vol. 20, No.1, pp. 8-19.

Rasmussen, B. (1995) Torsion in reinforced normal and high strength of concrete beams - Part I: Experimental test series. ACI Structural Journal, pp. 56-62.

Saravanan, P. - Abdeldelil, B. (2002) Torsional Behavior of Reinforced Concrete Beams Strengthened with FRP Composites. In: Proceedings of First FIB Congress, Osaka, Japan,13-19 Oct, 2002, pp. 1-11.

Rao, T.D.G. - Seshu, D.R. (2003) Torsion of steel fiber reinforced concrete members. Cement and Concrete Research, Vol. 33, 2003, pp. 1783-1788.

Rao, T.D.G. - Seshu, D.R. (2005) Analytical model for torsional response of steel fiber reinforced concrete members under pure torsion. Concrete and Cement composites 27, pp. 493-501.

Rao, T.D.G. - Seshu, D.R. (2006) Torsional response of fibrous reinforced concrete beams; Effect of single type reinforcement. Construction and Building Materials 20, pp. 187-192. 